\title{
Gallium lanthanum sulphide optical fibre for active and passive applications
}

\author{
D.W.Hewak, R.C.Moore, T.Schweizer, J.Wang, B.Samson, \\ W.S.Brocklesby, D.N.Payne and E.J.Tarbox
}

\begin{abstract}
The authors report on the first demonstration of optical fibres based on the Ga:La:S system. Core-clad structures have been fabricated by rod and tube method and pulled into lengths $>200 \mathrm{~m}$. Transmission over the wavelength range 1.0 to $6.5 \mu \mathrm{m}$, with fibre losses approaching the absorption and scattering level of the bulk glass, is obtained, opening the possibility of new fibre device applications of this promising glass host.

Chalcogenide glasses based on the sulphides has recently attracted considerable interest for their possible role as new optical fibre materials [1 - 5]. When doped with the rare-earths these glasses, by virtue of their low-phonon -energy and high refractive index, open up the possibility of new transitions and significantly increased pump efficiencies. Undoped sulphide glasses provide a waveguide with a transmission range which extends from the visible to wavelengths approaching $10 \mu \mathrm{m}$.

A variety of sulphide glass systems are under study, including those based on gallium and germanium sulphides [1 - 3], arsenic trisulphide [4] and chalcohalides which combine a sulphide and halide glassforming structure [5]. However, apart from arsenic trisulphide which suffers from poor rare-earth solubility, no optical fibre structures have been achieved in these materials. For the most part, the sulphide glasses tend to suffer from a propensity to devitrification, with the onset of crystallisation coinciding with the temperature for fibre- drawing.
\end{abstract}

Here we report, for the first time, on an optical fibre fabricated in the gallium-lanthanum glass system [6, 7]. This material provides an ideal host for the rare-earths, which substitute directly for the lanthanum ions, while at the same time providing a wide transmission range and a relatively stable and nontoxic glass matrix.

Gallium-lanthanum sulphide glass was prepared by melt quenching. Compositions were based on a molar ratio of $70 \%$ gallium and $30 \%$ lanthanum, with the ratio adjusted to modify the refractive index.

Substitutions of a few percent gallium sulphide for lanthanum sulphide were sufficient to raise the core glass index and allow guided modes to be supported by the structure. Analysis revealed residual oxide levels of $<0.5 \%$ in the starting materials. Transition metal impurities were of the order of a few parts per million and dominated by copper and iron. Both undoped glasses and glasses doped with praseodymium, erbium and dysprosium have been used in fibre drawing trials.

Both rods and preforms of the gallium lanthanum sulphide glass have been drawn into fibres. Bulk glass melts of core and cladding glasses in batches of $175 \mathrm{~g}$ were melted simultaneously. After quenching and annealing the ingots were cut and mechanically polished to form rods and tubes of diameter - $8 \mathrm{~mm}$ and 120 $\mathrm{mm}$ in length. Both solid rods and core-cladding structures formed by the rod in tube technique were used. These were then drawn using a conventional low temperature fibre drawing furnace at speeds up to $15 \mathrm{~m} / \mathrm{min}$. In some cases a UV cured acrylate coating was applied to the fibre during drawing. Uncoated fibre with a diameter of typically $125 \mu \mathrm{m}$ and $>200 \mathrm{~m}$ in length was obtained from a single preform. Coated fibre in lengths of several 10s of metres was also obtained. The fibre was mechanically strong and stable, showing no signs of devitrification or attack by moisture even after one year in our laboratories. The crosssection of a typical fibre is shown in Fig.1. 


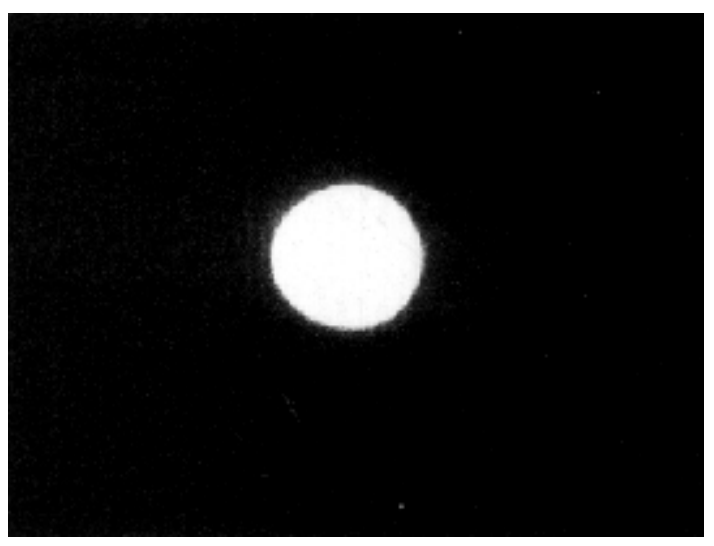

Loss measurements were performed first on bulk glass samples polished on two parallel faces. Three samples of length 5.9, 19 and 49mm were measured on a Fourier transform infra-red spectrometer, using in each case a shorter sample as a reference for correction to end reflection.

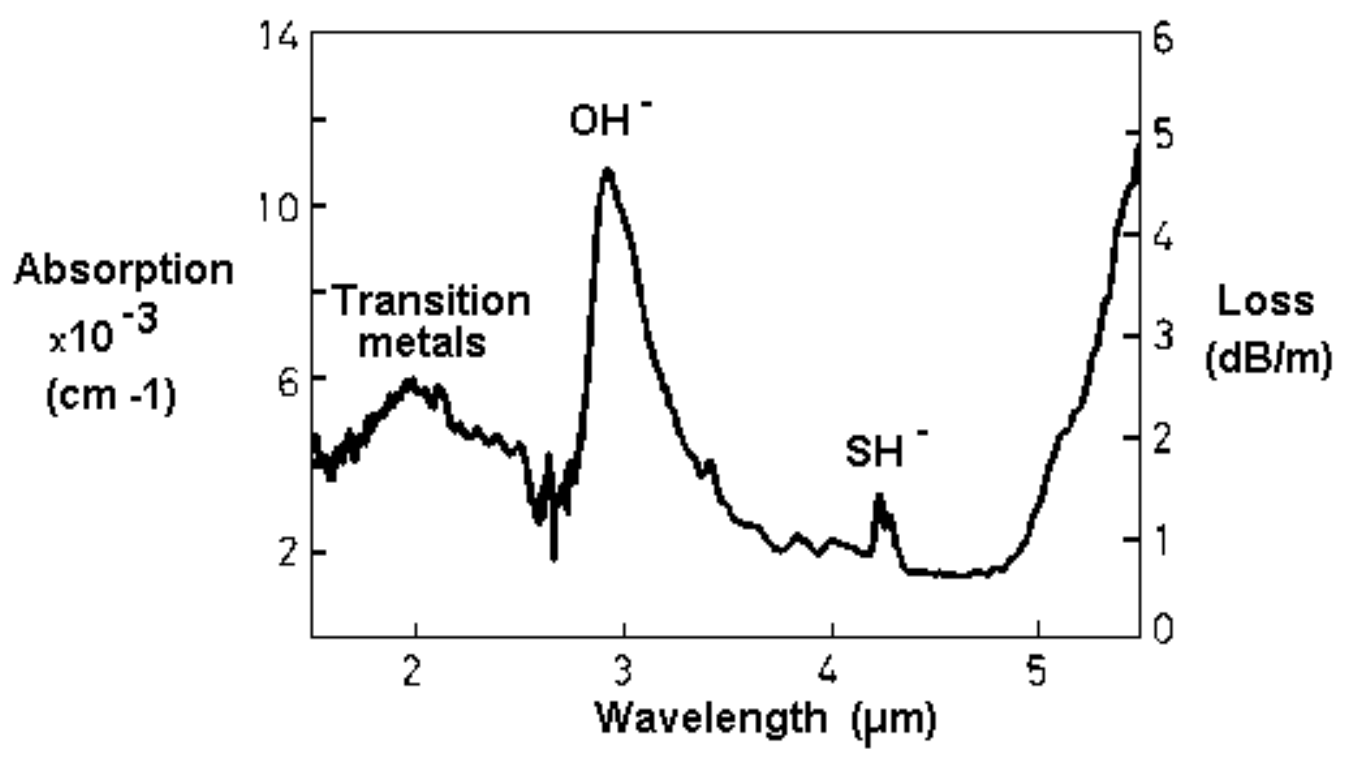

The absorption, normalised to a $1 \mathrm{~cm}$-thick sample, is shown in Fig. 2. Clearly visible in the spectrum are absorption bands which correspond to $\mathrm{OH}$, oxide impurities, $\mathrm{SH}$ and the transition metals. A background absorption of $1.8 \mathrm{~dB} / \mathrm{m}$ is indicated at $\sim 1 \mu \mathrm{m}$ and a loss of $<1.0 \mathrm{~dB} / \mathrm{m}$ at the intrinsic loss minimum at $\sim 4.5$ microns.

Fibre loss measurements were made on the same apparatus, modified with gold mirrors and a reflecting microscope object lens to allow measurement directly on an optical fibre. Transmission loss was estimated by the cutback method over a $63 \mathrm{~cm}$ section of praseodymium-doped multimode fibre clad. As shown in Fig. 3 , between the absorption bands a loss of $<5.0 \mathrm{~dB} / \mathrm{m}$ is measured at $1.34 \mu \mathrm{m}$ and $4.9 \mathrm{~dB} / \mathrm{m}$ at the intrinsic loss minimum at $\sim 4.7 \mu \mathrm{m}$.

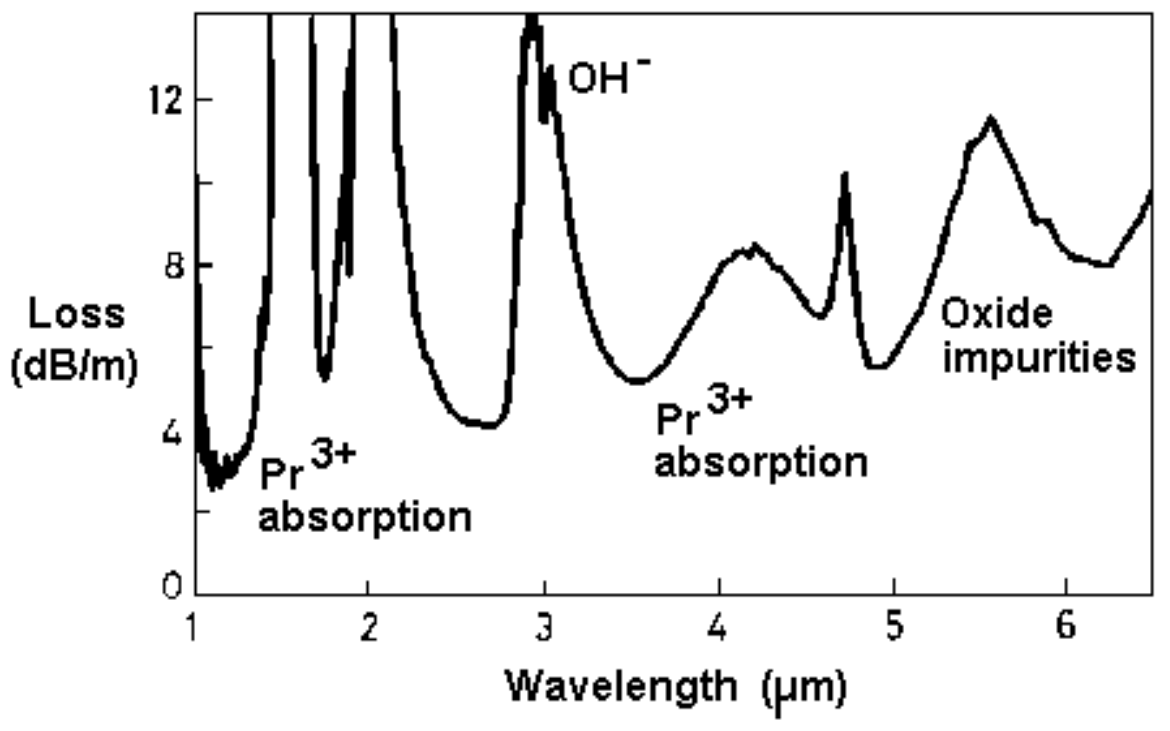


Across this wavelength range loss appears to be dominated by wavelength independent scattering. Around wavelengths independent scattering. Around wavelengths of $1-2 \mu \mathrm{m}$, loss is also affected by the intrinsic absorptions of the transition metal ions. We expect that this source of loss can be eliminated through careful; preparations of the starting materials, as was shown for fluoride glasses a decade ago [8]. A loss of $\sim 10 \mathrm{~dB} / \mathrm{m}$ is associated with the fundamental $\mathrm{OH}$ absorption at $\sim 3.0 \mu \mathrm{m}$. Measurements on undoped fibres have revealed SH absorptions of $<0.2 \mathrm{~dB} / \mathrm{m}$ at $4.05 \mu \mathrm{m}$. Efforts are under way to improve the glass melting procedure and thereby reduce the level of these impurities. Overall, these measurements indicate that with further improvements in the glass purity, the gallium lanthanum sulphide fibre will provide an optical waveguide covering the wavelength range from 1.0 to over $5.0 \mu \mathrm{m}$.

Power handling of these fibres was assessed by coupling to a Nd:YAG laser operating at $1064 \mathrm{~nm}$. A total of $5 \mathrm{~W}$ of power was guided through a core of $\sim 150 \mu \mathrm{m}$ with no decrease in transmission and no apparent laser damage. With their high glass transition temperature $\left(560^{\circ} \mathrm{C}\right.$ compared to $200-300^{\circ} \mathrm{C}$ in other sulphide glasses) these glasses offer the potential for greater power handling capacity and also reduced toxicity due to elimination of arsenic-containing compounds. This opens the range of applications to infra-red power delivery of medical, imaging or sensing applications.

Fluorescence has been measured in doped gallium lanthanum sulphide fibres and will be reported in a future publication.

To summarise, doped and undoped multimode fibres have been achieved in the gallium- lanthanum sulphide glass system. Fibre losses are approaching that of the bulk glass, and thus, with further materials purification, practical fibre device applications of this important new glass system are imminent.

\section{Acknowledgements}

Chalcogenide starting materials were supplied by Merck Ltd. Of Poole, England. This work was funded in part by Pirelli Cables Ltd. A UK DTI EPSRC Link programme, and by British Gas plc. We are grateful to S.Rutt and the Infrared Science and Technology Group for constructing the infra-red measurement apparatus.

Electronics Letters Online: No. 19960199

\section{References}

[1] QUIMBY. R.S., GAHAGAN. K.T., AITKEN, B.G., and NEWHOUSE. M.A.: 'Self-calibrating quantum efficiency measurement technique and application to $\mathrm{Pr}^{3+}$-doped sulphide glass', Opt. Lett., 1995, 20, pp. 2021-2023

[2] WEI, K., MACHEWIRTH. D.P., WENZEL, J., SNITZER, E., and SIGEL. G.H.: 'Pr ${ }^{3+}$-doped Ge-GaS glasses for 1.3 micron optical fibre amplifiers', Opt. Lett., 1994, 19, pp. 904-907

[3] SIMONS. D.R., FABER. A.J., and DE WAAL. H.:'GeS ${ }_{x}$ glass for $\mathrm{Pr}^{3+}$ doped fibre amplifiers at

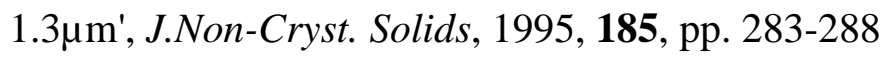

[4] OHISHI, Y., MORI, A., KANAMORI, T., FUJIURA, K., and SUDO. S.: 'Fabrication of praesodymium-doped arsenic sulfide chalcogenide fibre for $1.3 \mu \mathrm{m}$ fibre amplifiers', Appl. Phys. Lett., 1994, 65, pp. 13-15.

[5] MARCHESE. D., KAKARANATZAS. G., and JHA. A.: ${ }^{1} \mathrm{G}_{4}$ lifetimes, optical and thermal characteristics of Pr-doped $\mathrm{GeS}_{2}$-chalcohalide glasses', to be published in J. Non-Cryst. Solids

[6] BECKER, P.C., BROER, M.M., LAMBRECHT. V.G., BRUCE. A.J., and NYKOLAK. G.: Pr ${ }^{3+}$ : 'LaGa-S glass: A promising material for $1.3 \mu \mathrm{m}$ fibre amplification'. Tech. Dig. Topical Meeting Optical Amplifiers and their Applications, 1993, (Optical Society of America, Washington, DC), Postdeadline paper PDP5.

[7] HEWAK, D.W., MEDEIROS, J.A., SAMSON. B., BROWN. R.S., JEDRZEJEWSKI. P., WANG, J., TAYLOR, E., LAMING. R.I., WYLANGOWSKI, G., and PAYNE. D.N.: 'Quantum efficiency of 
praesodymium doped Ga:La:S glass for $1.3 \mu \mathrm{m}$ optical fibre amplifiers', IEEE Photonics Technol. Lett., 1994, 6, pp. 609-612

[8] MITACHI, S., TERUNUMA, Y., OHISHI. Y., and TAKAHAHI, S.: 'Reduction of impurities in fluoride glass fibres', J. Lightwave Technol., 1984, 2, pp. 587-592 